\title{
Tumor-Induced CD8+ T-Cell Dysfunction in Lung Cancer Patients
}

\author{
Heriberto Prado-Garcia, Susana Romero-Garcia, Dolores Aguilar-Cazares, \\ Manuel Meneses-Flores, and Jose Sullivan Lopez-Gonzalez
}

Departamento de Enfermedades Cronico-Degenerativas, Instituto Nacional de Enfermedades Respiratorias Ismael Cosío Villegas, Calzada de Tlalpan 4502, Seccion XVI, 14080 Mexico City, Mexico

Correspondence should be addressed to Heriberto Prado-Garcia, hpradog@yahoo.com

Received 11 July 2012; Revised 28 August 2012; Accepted 4 September 2012

Academic Editor: Nejat Egilmez

Copyright () 2012 Heriberto Prado-Garcia et al. This is an open access article distributed under the Creative Commons Attribution License, which permits unrestricted use, distribution, and reproduction in any medium, provided the original work is properly cited.

Lung cancer is the leading cause of cancer deaths worldwide and one of the most common types of cancers. The limited success of chemotherapy and radiotherapy regimes have highlighted the need to develop new therapies like antitumor immunotherapy. CD8+ T-cells represent a major arm of the cell-mediated anti-tumor response and a promising target for developing T-cell-based immunotherapies against lung cancer. Lung tumors, however, have been considered to possess poor immunogenicity; even so, lung tumor-specific CD8+ T-cell clones can be established that possess cytotoxicity against autologous tumor cells. This paper will focus on the alterations induced in CD8+ T-cells by lung cancer. Although memory CD8+ T-cells infiltrate lung tumors, in both tumorinfiltrating lymphocytes (TILs) and malignant pleural effusions, these cells are dysfunctional and the effector subset is reduced. We propose that chronic presence of lung tumors induces dysfunctions in CD8+ T-cells and sensitizes them to activation-induced cell death, which may be associated with the poor clinical responses observed in immunotherapeutic trials. Getting a deeper knowledge of the evasion mechanisms lung cancer induce in CD8+ T-cells should lead to further understanding of lung cancer biology, overcome tumor evasion mechanisms, and design improved immunotherapeutic treatments for lung cancer.

\section{Introduction}

Lung cancer is the leading cause of cancer-related mortality in developed countries and the second leading cause of death in countries with emerging economies. Worldwide, lung cancer is one of the most commonly diagnosed neoplasias, representing $13 \%$ of all cancer cases and approximately $18 \%$ of all cancer deaths [1-3]. In countries with emerging economies, the adoption of cancer-associated lifestyles such as reduced physical activity, smoking, unhealthy dietary habits, the increased air pollution, and an aging population has led to a boost in the prevalence of lung cancer $[1,2,4]$.

Lung carcinomas are classified as either of two types: small cell lung carcinoma (SCLC) and non-SCLC (NSCLC). NSCLC accounts for approximately $85 \%$ of all lung cancer cases and includes three histological subtypes: squamous cell carcinoma, adenocarcinoma, and large cell carcinoma. Treatment of NSCLC involves surgery in the early stages, chemotherapy with concurrent radiation for some locally advanced cancers, and palliative chemotherapy for metastatic disease. In developing countries, most lung cancer diagnoses are performed at advanced stages of lung malignancy and therefore 5-year survival rates remain low $[4,5]$.

The limited success of chemotherapy has emphasized the need to develop new therapeutic strategies such as immunotherapy. However, the multifaceted nature of the immune escape mechanisms of lung tumor cells is a major obstacle to the potential application of immunotherapy in lung cancer patients. There is a need, therefore, to elucidate and characterize these immune escape mechanisms to develop strategies to counteract them, thus enhancing the efficacy of T-cell-based immunotherapies.

Several tumor evasion mechanisms to immune responses have been reported [6]; however, few have been shown to participate in lung cancer. In a recent paper, Ding and Zhou [7] described the role of CD4+ T-cells and their subsets in tumor immunity. In this review, we focus on the alterations induced by lung tumors on CD8+ T-cells. 


\section{Chronic Inflammation and Immunosuppression in Lung Cancer}

Chronic inflammation has been associated with increased risk of tumor development and progression. Tumor promoting factors, such as protein and DNA damage through oxidative stress, as well as, angiogenesis and tissue remodeling, are induced by chronic inflammation. Substances such as asbestos, cigarette smoke, and wood smoke are known to cause a chronic inflammatory state, which in turn promotes tumorigenesis [8]. Also, pulmonary disorders such as chronic obstructive pulmonary disease (COPD)/emphysema and pulmonary fibrosis, which are associated with greater risk for developing lung cancer, are characterized by abundant and deregulated inflammation $[9,10]$.

Cancer induces non-MHC-restricted inflammatory responses in the host, as in most chronic diseases; both the innate and adaptive components of the immune response play a role in the control of tumor growth and metastasis [8]. However, tumors impair the inflammatory responses and take advantage of the responses to promote tumor survival, proliferation, and metastasis. Therefore, the presence of leukocytes within a tumor may be a consequence of an inflammatory reaction that supports either the spread of tumor cells or the protective host antitumor immune responses [11]. The immunoediting theory has been proposed to explain the interaction between tumor cells and the immune system. This theory involves three phases: elimination, equilibrium, and escape [12, 13].

Lung tumors have been considered poorly immunogenic and incapable of inducing an immune response. One factor that may contribute to this low responsiveness is smoking, which is well known for increasing the risk of developing lung cancer. Smoking has been shown to exert several proinflammatory effects on immunity [14]. For example, smoking increases production of several proinflammatory cytokines such as Tumor Necrosis Factor-alpha (TNF- $\alpha$ ), Interleukin 1 (IL-1), IL-6, and IL-8 and decreases anti-inflammatory cytokines, such as IL-10. Proinflammatory cytokines IL-6 and TNF- $\alpha$ are associated with chronic inflammation and immunosuppression [8].

Dendritic cell (DC) maturation is inhibited by cigarette smoking, as demonstrated by reduced cell surface expression of MHC class II and the costimulatory molecules CD80 and CD86. Consequently, DCs from cigarette smoke-exposed animals show reduced capacity to stimulate and activate antigen-specific T-cells in vitro; this phenomenon is consistent with a reduced antigen-specific T-cell proliferation in smoke-exposed mice observed in vivo [15]. Smokeinduced defects in DC function may lead to impaired T-cell function and inhibit tumor immunosurveillance $[14,15]$. Moreover, asbestos, which is another factor associated to increased risk for developing tumors such as mesothelioma and lung cancer, has been reported to promote reduction of antitumor immunity. Asbestos reduces interferon-gamma (IFN- $\gamma$ ) production in stimulated CD4+ T-cells in vitro; also, asbestos reduces the expression of chemokine receptors such as CXCR3, which is expressed by memory T-cells and macrophages [16]. IFN- $\gamma$ induces CXCR3 ligands expression among which the chemokine CXCL10 has been shown to inhibit NSCLC tumorigenesis and spontaneous metastases [17].

However, there is circumstantial evidence that immunosuppression is a risk factor for developing lung cancer. Within the population of HIV-positive patients the incidence of lung cancer has been estimated to be 2 to 4 times higher with respect to that of the general population. Several factors, including viral load, CD4+ T-cell count, immunosuppression, and smoking, have been linked to development of lung cancer in these patients [18-20]. Moreover, tobacco and immunosuppression are risk factors for developing lung cancer after liver transplantation [21]. In another study by Engels et al. [22], lung cancer risk, among other carcinomas such as liver and kidney carcinomas, was reported to be higher in recipients receiving solid organ transplantation. Taken together these reports suggest that the immune system might control to some extent development of lung tumors.

\section{Lung Cancer and Pleural Effusion}

A frequent inflammatory condition present in lung cancer, particularly in lung adenocarcinomas, is the formation of pleural effusions as a consequence of tumor invasion of the pleura in late stages of cancer. Liquid accumulation in this compartment leads to the formation of a pleural effusion, which occurs in $15 \%-20 \%$ of primary lung cancer cases. In these patients, the pleural effusion is detected as an amount of fluid varying between 300 and $1500 \mathrm{~mL}$. Appearance of pleural effusion is an ominous prognostic sign for lung cancer patients, because the presence of this condition is associated with a poor prognosis with a median survival of 4 months [23].

Cytology studies of pleural effusions indicate that most of these effusions contain high proportions of both neoplastic and inflammatory cells $[24,25]$, which makes this biological material a suitable model for studying the host immune system and malignant cell interactions [24-28]. Tissue samples collected by biopsies limit the amount of material obtained, and therefore it is not possible to perform concurrent phenotyping, quantification, and functionality studies on distinct immune cells in tumor-infiltrating lymphocytes (TILs) from the same tissue sample [29]. Conversely, the ex vivo model using immune cells from malignant effusions allows to study the effects of tumor cell-mediated alterations in T-cells. Data obtained from the study of malignant effusion provide a comprehensive and integral vision of the effects of tumor cell-mediated alterations in distinct subpopulations of Tcells and particularly in CD8+ T-cells.

\section{Tumor-Associated Antigens in Lung Cancer}

During oncogenesis, transformed cells gradually acquire mutations and epigenetic alterations that increase the quantity of antigens expressed in normal tissue, mutated proteins, novel epitopes encoded within alternative open reading frames, intronic sequences, or products that result from protein splicing. These antigens are collectively designated 
as tumor antigens. Tumor-associated antigens were initially characterized in melanoma by analyzing TILs [30, 31]. The identification of tumor-associated antigens has enabled the development of vaccines that induce a potent antigenspecific CD8+ T-cell response against tumors [30, 32].

The consensus is that tumors express at least five types of antigens that can be recognized by the immune system: (a) antigens coded by oncogenic viruses. (b) MHCrestricted tumor-associated peptides shared by histologically distinct tumors and silent in normal tissues, except for germ cells in the ovaries and testes $[30,31]$. In lung cancer, melanoma-specific antigen A3 (MAGE A3) is one of the best characterized [33]. (c) Overexpressed antigens such as survivin [34] and Wilms' tumor gene WT1 product are some of the few identified in lung tumors [31, 35, 36]. (d) Differentiation-specific antigens such as melanomaand melanocyte-associated tyrosinase-1. In lung cancer, differentiation antigens have not been identified so far [31]. (e) Unique antigens are generated by point mutations in ubiquitously expressed genes and regulate key cellular functions. Some mutated antigens reported in lung cancer are p53 [37], the elongation factor 2 gene [38], actinin-4 [39], malic enzyme [40], and NF-YC [31, 41].

Melanoma has been considered an "immunogenic" tumor due to the presence of antitumor immune cells within the tumor tissue, the identification of tumor antigens that are capable of being recognized by the host [31, 42], and the clinical benefits reported with the application of some immunotherapeutic schemes [32]. In contrast, lung cancers show a low infiltration of TILs. Qualitative and quantitative abnormalities in the distinct immune cells infiltrating lung tumors, and particularly in CD8+ T-cells, have also been reported [43-46]. One of the most common evasion mechanisms against CD8+ T-cells in cancer is loss or downregulation of HLA molecules expression. Lung cancer cells have been shown to downregulate HLA I expression which may lead to develop cancer $[47,48]$. Also, the application of lung tumor antigens have had limited success as antitumoral vaccines against lung cancer $[49,50]$. For these reasons, lung tumors have been considered poorly immunogenic. However, lung tumors express tumor associated antigens, which can be recognized by the CD8+ T-cells of the host immune system. Several studies have reported that cytotoxic $\mathrm{T}$ lymphocyte clones can be established; these clones are MHC class I-restricted and show specific cytotoxicity against autologous target cells [51-55]. Thus, the poor immune response observed against lung cancer may be attributed to the evasion mechanisms presented by lung tumor cells.

\section{CD8+ T-Cells Infiltrating Lung Tumors}

CD8+ T-cells are a crucial component of the cellular immune response, which is necessary for the control of a variety of bacterial and viral infections. These cells also represent a major arm of the cell-mediated antitumor immune response [56]. CD8+ T-cell protection is mediated by its ability to specifically target host cells compromised by microbial infection or oncogenic transformation. Following exposure to antigens by DCs in an appropriate inflammatory environment, CD8+ T-cells undergo a period of massive expansion, activation, and differentiation to terminally differentiated cells with effector functions. Once the pathogenic process is resolved, most effector CD8+ T-cells undergo apoptosis, leaving a long-lived subset of memory cells. These cells possess an enhanced ability to control secondary exposures to antigens [32, 57, 58], which is attributed to their increased frequency, rapid acquisition of effector functions, and recruitment to the tumor sites. In both animal models and humans, CD8+ T-cells have been shown to play an important role in the host's defense against malignancies [59]. Therefore, most cancer vaccine strategies have focused on the induction of effector CD8+ T-cells that kill tumor cells $[30,32]$.

TILs have been shown to contribute to the clinical outcome of human cancers. A high infiltration of T-cells is associated with good clinical outcome in many different kinds of cancers. In tumors such as colorectal cancer $[60,61]$ and ovarian carcinoma [62], high densities of intratumoral memory $(\mathrm{CD} 45 \mathrm{RO}+)$ cells and CD8+ T-cells are localized and correlate with favorable prognosis.

Accordingly, some reports show that the presence of TILs with memory phenotype in lung cancer is predictive of a favorable clinical outcome [44, 46, 63, 64]. Ruffini et al. [65] showed that CD8+ T-cells were associated with prolonged survival in lung cancer; this association was only found in squamous cell carcinomas. In another study, CD8+ T-cell infiltrations were observed predominately along the invasive margin (peritumoral distribution) as well as within lymphoid aggregates that are formed at adjacent stromal tissue, which have been termed as tertiary lymphoid structures [44]. These tertiary lymphoid structures are associated with longterm survival in lung cancer patients [44].

Interestingly, Wakabayashi et al. [43] showed that high numbers of CD4+ T-cells, but not CD8+ T-cells, within cancer cell nests are positively correlated with favorable prognosis in lung cancer patients. This finding suggests that $\mathrm{CD} 4+\mathrm{T}$-cells may be required for initiating and maintaining antitumor immune responses; given that, without CD4+ Tcell help, the resultant CD4-unhelped CD8+ T-cells do not differentiate into sustainable memory cells [57]. Hiraoka et al. [66] found a synergistic effect of simultaneous high CD4+ and CD8+ T-cell infiltrations in cancer stroma, from resected tumor specimens, as a favorable prognostic factor in lung cancer patients. Nevertheless, more recently, AlShibli et al. [64] showed that high densities of CD8+ Tcells in the stroma significantly correlated with an improved survival in patients with NSCLC (stages I to IIIa). This correlation was found to be independent of infiltrating CD4+ T-cells. Even though the role of infiltrating CD4+ T-cells as an independent factor predicting favorable outcome is still controversial, these studies suggest that low infiltration of CD8+ T-cells is associated with a poor clinical outcome in lung cancer patients.

A similar behavior has been found in the pleural compartments of lung cancer patients. Our group and other authors have reported that the CD8+ T-cell subpopulation 
in pleural effusion is reduced, while the CD4+ T-cell subpopulation is increased [24, 27, 67].

The phenotyping of pleural effusion CD8+ T-cells from lung cancer patients shows an elevated population of memory (CD45RA-CD45RO+CD27+CD28+) CD8+ Tcells and a low proportion of terminally differentiated (CD45RA+CD45RO-CD27-CD28-) CD8+ T-cells, which is similar to data from TILs. The selective recruitment of memory CD8+ T-cells in lung tumors may be related to the presence of chemotactic factors for this subset (e.g., CCL21, CCL5 and CCL2), as has been reported by de Chaisemartin et al. [68].

Even though memory CD8+ T-cells infiltrate lung tumors, both in TIL and malignant effusions, the CD8+ Tcells are functionally impaired and are poorly responsive or unresponsive to several T-cell-activating stimuli. CD8+ Tcells have reduced proliferation rate, diminished production of some Th1 cytokines, and reduced cytotoxic potential [24, $45,69]$. These findings suggest that CD $8+T$-cells, located in contact or in proximity to the tumor, are profoundly affected by tumor-derived factors compared with those CD8+ T-cells located in sites that are more distant from the tumor.

CD8+ T-cells from both TILs and pleural effusions share a similar pattern of dysfunctions. Due to the advanced stage of lung cancer, the evasion mechanisms of lung tumors may be comparable at the local level (tumor in situ) and at the pleural compartment (metastatic tumor). Thus, the study of malignant effusions may provide future insight into the interaction between tumor cells and immune cells.

Effector CD8+ T-cells should be present at the tumor sites eliminating the lung tumor cells. Their absence may be because tumor cells block the differentiation process from memory cells to terminally differentiated CD8+ T-cells. This phenomenon may be mediated by the following; see Figure 1.

(i) Immunosuppression factors in the microenvironment. Lung cancer cell lines release immunoregulatory cytokines such as IL-10 and Transforming Growth Factor beta (TGF- $\beta)[70,71]$ as well as enzymes that catabolize amino acids that are important for T-cell effector functions (e.g., indoleamine2,3-dioxygenase, IDO, and arginase) [6, 72].

(ii) Deficient tumor antigen presentation by DCs due to the absence of tumor-infiltrating DCs or to the segregation of DCs, which hinders their migration to and maturation in the lymphatic node, thereby blocking induction of an antitumor immune response.

(iii) Reduced production of cytokines by helper CD4+ Tcells for costimulation of CD8+ T-cells, such as IL-15 $[73,74]$.

(iv) Suppression induced by lung tumors through the recruitment of regulatory $\mathrm{T}$-cells (Tregs) or other regulatory populations, such as myeloid suppressor cells. Tregs play an active role in establishing and maintaining immunological unresponsiveness to self-constituents and negative control of various immune responses to nonself-antigens. Tregs, identified as CD4+CD25, CD4+CD25+FOXP3+ or CD4+CD25+CD127- T-cells, have been found in pleural effusions as well as in TILs from lung cancer patients [75-79]. Recently, tumor infiltrating FOXP3+ cells have been associated with low overall and relapse-free survival in NSCLC [78]. Nevertheless, studies which associate CD8+ T-cell with Tregs infiltration in lung cancer have not been done so far.

(v) Downregulation of $\mathrm{CD} 3 \varepsilon$ expression in memory CD8+ T-cells. A deficiency in CD $3 \varepsilon$ has been reported by our group in pleural effusion CD8+ Tcells from lung cancer patients $[80]$. CD $3 \varepsilon$ is an essential component of the CD3 complex, which is responsible for translating the TCR signaling. The reduced expression of the $\mathrm{CD} 3 \varepsilon$ chain may block the terminal-differentiation program of CD8+ T-cells. Accordingly, T-cells isolated from the lung tumor microenvironment are nonresponsive to triggering through the TCR, which can be reversed by IL-12 [81]. However, IL-12 administered in situ in murine lung tumors induces T-cell death [82].

An efficient generation of effector CD8+ T-cells ideally leads to clearance of the tumor cells. In a variety of infections in mouse and primates, pathogens have been shown to escape immune control and become persistent through the long-term antigenic stimulation of responding CD8+ T-cells. Chronic stimulation results in a progressive loss of the effector function of CD8+ T-cells and the expression of markers associated with T-cell exhaustion, such as the PD-1 coinhibitory molecule [83-85]. In addition, chronic stimulation has been shown to sensitize CD8+ T-cells to activation-induced cell death (AICD) [85]. A similar phenomenon has been observed in some tumors; for example, in melanoma, CD8+ T-cells specific for MART-1 express higher levels of PD-1 and reduced levels of IL-2 and IFN- $\gamma$ [86]. In mouse tumor models, the blockade of PD-L1 leads to increased expansion of tumor-specific T-cells and decreased numbers of apoptotic T-cells [83]. Pleural effusion CD8+ T-cells from lung cancer patients express cell markers associated with a memory-like phenotype (CD45RA-CD45RO+CD27+Granzyme A ${ }^{\text {low }}$ Perforin-), similar to those markers found in CD8+ T-cells from chronic viral infections, which suggests that CD8+ T-cells may be exhausted [85]. Recently, Zhang reported that CD8+ T-cells from TILs of NSCLC showed increased expression of PD-1 [87]. Thus, the continued presence of the tumor may sensitize memory CD8+ T-cells to AICD before they reach the effector stage. However, the evaluation of exhaustion in lung tumor-specific CD8+ T-cells has not been possible because lung tumor-associated antigens are not expressed in all cancer patients. Nevertheless, clinical trials using PD-1-blocking antibodies are underway for NSCLC [88].

\section{CD8+ T-Cells Are Impaired in Their Lytic Function}

The perforin-granzyme (or granule exocytosis) pathway is the classic effector mechanism that CD8+ T-cells and NK 
cells use to lyse target cells. This pathway is responsible for the elimination of intracellular bacterial and viral infections and for tumor cell destruction. Perforin and granzymes are highly expressed in terminally differentiated CD8+ T-cells [56].

Reduced numbers of perforin- and granzyme-positive cells have been observed in TILs from lung cancer patients using immunohistochemistry methods, suggesting that TILs are dysfunctional [89]. However, memory (CD45RO+) CD8+ T-cells express low levels of perforin $[90,91]$; thus the low expression of this molecule in TILs may reflect the fact that terminally differentiated cells infiltrating tumor cells are present in low proportions. Nevertheless, the impaired expression of perforin compared with granzyme A has been found by our group in terminally differentiated CD8+ T-cells from malignant pleural effusion and to a lesser extent in the corresponding CD8+ T-cell subset from peripheral blood of lung cancer patients [24].

Cytolytic activity from both TILs and pleural effusion lymphocytes has been determined using autologous tumor cells. TILs from lung cancer patients present poor cytolytic activity against autologous tumor cells, which is recovered after treating T-cells with recombinant IL-2 [46]. Also, pleural effusion T-cells from lung cancer patients have been shown to exhibit poor cytolysis against autologous tumor, Daudi and K562 cells. Similar to TILs, stimulation with anti-CD3 and IL-2 restored cytotoxicity against tumor cells $[28,92]$. IL-15 induces the proliferation of memory CD8+ T-cells independently of antigen and increases their effector function [93]; accordingly, malignant pleural effusion T-cells treated with IL-15 exert cytolysis against autologous tumor cells [69]. Combinations of other stimuli such as IL-2 plus IL-7, IL-2 plus IL-12, or IL-2 plus TCR-CD3 engagement also reverse the immunosuppressed state of pleural effusion T-cells; remarkably, cytolysis of autologous tumor cells is mainly mediated by CD8+ T-cells [94].

These data support the conclusion that, in lung cancer, terminally differentiated CD8+ T-cells have a defective cytolytic function, which can be restored by using a combination of cytokines and TCR-engagement stimuli. Chronic stimulation results in the loss of effector CD8+ T-cell function; perforin and granzyme expressions are downregulated in viral infections [83]. Similar alterations in CD8+ T-cells may be associated with chronic stimulation of immune cells by lung tumors.

\section{CD8+ T-Cell Death in Lung Cancer: The Role of AICD}

Numerous studies have demonstrated that a high frequency of T-cell apoptosis occurs in several types of cancer; in particular, CD8+ T-cells are more susceptible to apoptosis [95-97]. Remarkably, T-cell death is not limited to the tumor site because increased apoptosis has been found in Tcells from peripheral blood of patients with head and neck carcinomas, breast carcinomas, or melanomas [95-97]. In lung cancer, cell death of the effector CD8+ T-cell subset may be responsible for its reduced presence; given that a high percentage of pleural effusion and peripheral blood CD8+ T-cells express Fas. This phenomenon may lead to the apoptosis of Fas-expressing CD8+ T-cells when they reach the terminally differentiated stage.

We recently found that peripheral blood CD4+ and CD8+ T-cells from lung cancer patients show a high susceptibility to spontaneous apoptosis compared with T-cell subpopulations from healthy donors. This phenomenon is mainly observed in CD8+ T-cells. Nevertheless, susceptibility to spontaneous apoptosis does not lead to a reduction of the CD8+ T-cell subpopulation in peripheral blood $[24,98]$.

The Fas/Fas ligand (FasL) pathway has been proposed to be responsible for the spontaneous apoptosis observed in T-cells. Peripheral blood CD8+ T-cells from cancer patients increase apoptosis after the engagement of the Fas receptor $[95,99,100]$. However, no apoptosis of CD4+ and CD8+ Tcells from lung cancer patients was observed after treatment with agonistic anti-Fas antibodies [101].

The binding of the Fas ligand (FasL) on the tumor cell to the Fas receptor on the T-cell, a hypothesis known as tumor counterattack, has been suggested as responsible for Tcell death [100]. Though controversial, several reports have shown that a variety of human tumors express and secrete functional FasL (contained in microvesicles). However, other authors and our group have reported that lung cancer cells do not express FasL. This has been demonstrated in lung cancer cell lines, tumors cells from pleural effusions, and resected tumor tissue $[80,102]$. Thus, spontaneous apoptosis in lung cancer is not mediated by the Fas receptor; other death receptors (TNFR1, DR4, DR5, etc.), however, may induce this phenomenon. In addition, spontaneous apoptosis may be the consequence of other factors (described below) that are systemically released by tumor or stromal cells.

Tumor cells release tumor antigens that chronically stimulate CD8+ T-cells $[103,104]$. This chronic stimulation may sensitize CD8+ T-cells from lung cancer patients to AICD as has been shown in TILs from various types of human $[55,105,106]$ and murine tumors $[107,108]$. Chemokines, cytokines or other soluble factors secreted by lung tumors or stromal cells may also induce and amplify non-HLA restricted inflammatory responses, leading to an increased susceptibility to AICD in CD8+ T-cells.

Accordingly, we recently reported that CD8+, but not CD4+, T-cells from malignant pleural effusions undergo AICD and this phenomenon is not observed in peripheral blood CD4+ and CD8+ T-cells [101] (see Figure 2). We found that AICD is associated with the upregulation of FasL and TRAIL expression and reduced the expression of the antiapoptotic molecule Bcl-2 [101]. FasL expression has also been found in TILs from lung tumors [102]. AICD is preferentially observed in memory and terminally differentiated CD8+ T-cells. In contrast, memory CD8+ Tcells from healthy donors have been shown to be resistant to AICD $[109,110]$.

Polyclonal stimulation of pleural CD8+ T-cells leads to AICD, a phenomenon that potentially involves both tumorand nontumor-specific CD8+ T-cells. Kilinc et al. [82], in a murine lung tumor model, observed that intratumoral delivery of IL-12 results in the activation and subsequent 


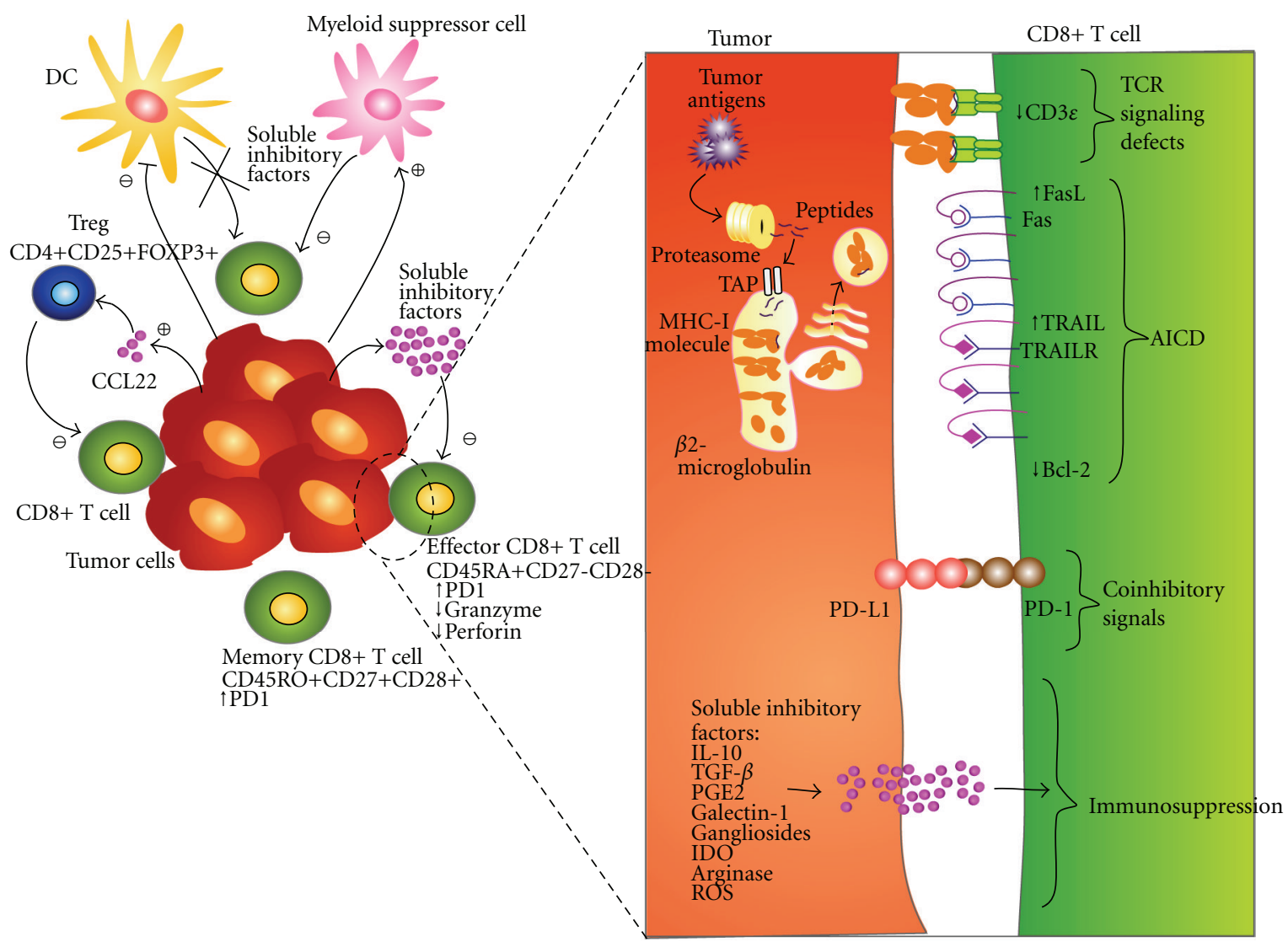

FIGURE 1: Alterations induced in the CD8+ T-cells by lung cancer. Tumor, stroma, cells, and soluble factors in the microenvironment inhibit DCs recruitment and induce the presence of immune cells with suppressor activity, such as myeloid suppressor cells and Tregs, which results in (1) blocking the differentiation program of CD8+ T-cells keeping them in a memory stage and diminishing the terminally-differentiated CD8+ T-cell subset, (2) reduced expression of cytolytic molecules granzymes and perforin, (3) reduced expression of CD3e, altering the signaling pathway through TCR ligation, (4) PD-L1/PD-1 interaction that induces on CD8+ T-cell decreased TCR-mediated proliferation and cytokines production, (5) sensitization of CD8+ T-cell to apoptosis mediated by AICD.

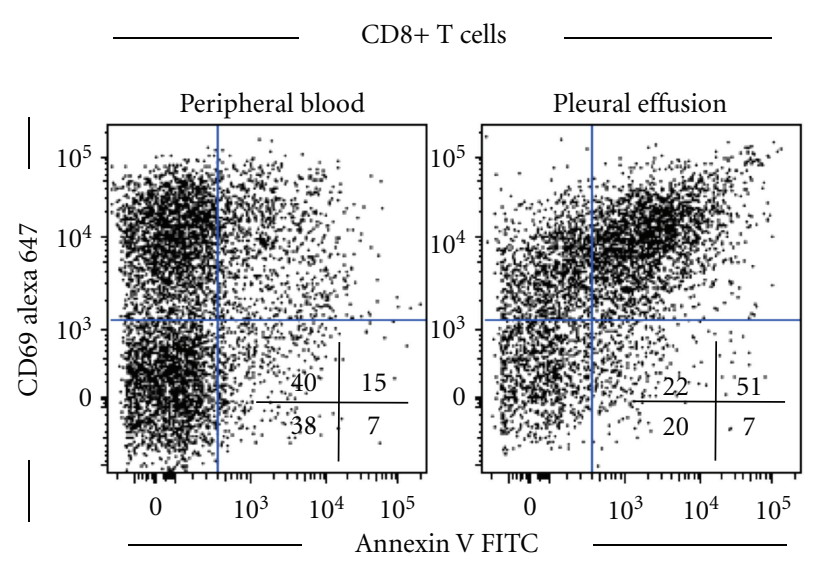

(a)

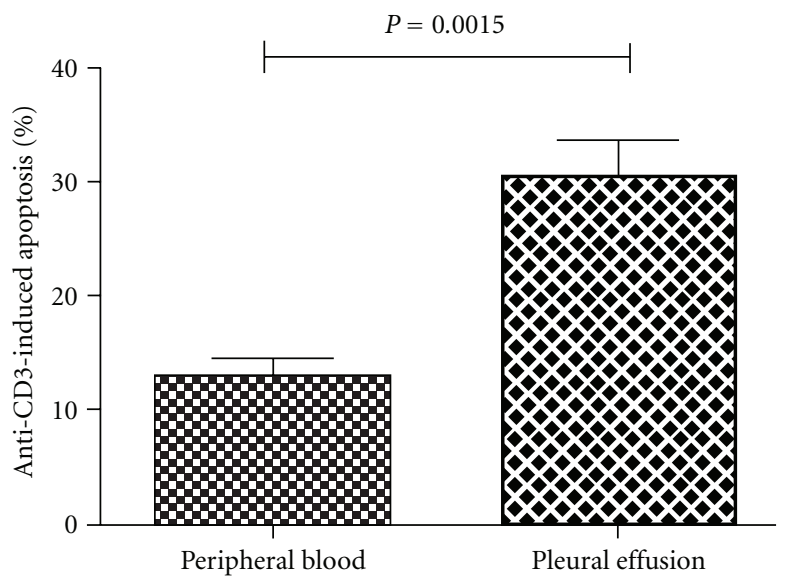

(b)

Figure 2: Pleural effusion, but not peripheral blood, CD8+ T-cells from lung cancer patients are sensitive to AICD. Both pleural effusion and peripheral blood CD8+ T-cells from lung cancer patients $(n=10)$ were stimulated with anti-CD3 mAbs for 24 h; then apoptosis was determined by annexin V binding in activated CD8+CD69+ T-cells by multiparametric flow cytometry; propidium iodide was used to exclude necrotic cells. (a) Results from a lung cancer patient. (b) Anti-CD3 induced apoptosis was determined as described in [101], comparison was made by paired Student's $t$-test. Bars depict the mean \pm Standard Error. 
death of total effector/memory CD8+ T-cells in situ. The factors that can contribute to the increased susceptibility of pleural effusion CD8+ T-cells to AICD are the following: (a) gangliosides released by lung tumor or stromal cells, given that these molecules sensitize activated T-cells to apoptosis in vitro $[111,112]$; (b) diminished levels of CD3 $\varepsilon$ in CD8+ T-cells may lead to the dysfunction of CD8+ T-cell responses and enhanced T-cell apoptosis [80]; (c) the chronic presence of tumor antigens and damage associated molecular patterns (DAMPs) secreted by tumor or stromal cells in the pleural compartment. DAMPs have been shown to induce a high production of reactive oxygen and nitrogen species, which damage the memory or terminally differentiated CD8+ Tcells [113-115].

Therefore, the susceptibility to AICD of malignant effusion-derived memory CD8+ T-cells may prevent these cells from becoming terminally differentiated. In a similar way, nonantigen-specific CD8+ T-cells become susceptible, in a bystander fashion, to AICD after TCR stimulation in some viral infections [116]. Bystander sensitization to AICD has been proposed as a mechanism for immune deficiencies associated with persistent viral infections involving chronic T-cell responses [116]. In lung cancer patients, a similar but deregulated phenomenon may explain the susceptibility to AICD of CD8+ T-cells in the pleural compartment [24].

\section{Concluding Remarks}

Several clinical trials have been conducted using intrapleural administration of diverse combinations of biological response modifiers to increase the host immune response against tumor cells [117-119]. However, these treatments have failed to show significant clinical benefits in terms of patient survival or quality of life. Another approach in immunotherapeutic treatment is adoptive cell transfer, in which immune cells from cancer patients are expanded $e x$ vivo. These cells are then infused back into the patient with the hope that they reach the tumor and induce tumor cell death. This approach has been attempted in a number of clinical trials for lung cancer with little success $[120,121]$. The susceptibility to AICD of CD8+ T-cells may explain the limited success of these therapies; thus, blocking the apoptotic loop is essential for the success of T-cell-based immunotherapeutic regimens for patients with lung cancer.

The role that CD8+ T-cells plays against tumor cells is crucial. However, based on the information presented above, lung tumor cells induce on CD8+ T-cells a series of quantitative and qualitative alterations that hamper their full participation in tumor recognition and destruction (see Figure 1). As similar alterations are found both in primary as in metastatic tumors (pleural effusions), the amount of tumor and immune cells interacting in this anatomical compartment allow a more integral and complete study of the several evasion mechanism shown by lung tumor cells.

Getting a deeper knowledge of the evasion mechanisms that lung cancer induces in the cells of the immune system, and particularly in CD8+ T-cells, should lead to further understanding of lung cancer biology, downregulation of evasion mechanisms due to tumor cells and design of improved immunotherapeutic CD8+ T-cell-based regimes.

\section{Conflict of Interests}

The authors declare that there are no conflict of interests.

\section{Acknowledgment}

This work was supported by Conacyt Grant 167623.

\section{References}

[1] A. Jemal, F. Bray, M. M. Center, J. Ferlay, E. Ward, and D. Forman, "Global cancer statistics," CA Cancer Journal for Clinicians, vol. 61, no. 2, pp. 69-90, 2011.

[2] J. Ferlay, H. R. Shin, F. Bray, D. Forman, C. Mathers, and D. M. Parkin, "Estimates of worldwide burden of cancer in 2008: GLOBOCAN 2008," International Journal of Cancer, vol. 127, no. 12, pp. 2893-2917, 2010.

[3] J. Ferlay, H. R. Shin, F. Bray, D. Forman, C. Mathers, and D. M. Parkin, GLOBOCAN, 2008 V1. 2, Cancer Incidence and Mortality Worldwide: IARC CancerBase No. 10, International Agency for Research on Cancer, Lyon, France, 2010, http://globocan.iarc.fr.

[4] J. R. Molina, P. Yang, S. D. Cassivi, S. E. Schild, and A. A. Adjei, "Non-small cell lung cancer: epidemiology, risk factors, treatment, and survivorship," Mayo Clinic Proceedings, vol. 83, no. 5, pp. 584-594, 2008.

[5] A. J. Alberg, J. G. Ford, and J. M. Samet, "Epidemiology of lung cancer: ACCP evidence-based clinical practice guidelines (2nd edition)," Chest, vol. 132, no. 3, pp. 29S-55S, 2007.

[6] G. A. Rabinovich, D. Gabrilovich, and E. M. Sotomayor, "Immunosuppressive strategies that are mediated by tumor cells," Annual Review of Immunology, vol. 25, pp. 267-296, 2007.

[7] Z. C. Ding and G. Zhou, "Cytotoxic chemotherapy and CD4+ effector T cells: an emerging alliance for durable antitumor effects," Clinical and Developmental Immunology, vol. 2012, Article ID 890178, 12 pages, 2012.

[8] A. Mantovani, P. Allavena, A. Sica, and F. Balkwill, "Cancerrelated inflammation," Nature, vol. 454, no. 7203, pp. 436444, 2008.

[9] R. O'Donnell, D. Breen, S. Wilson, and R. Djukanovic, "Inflammatory cells in the airways in COPD," Thorax, vol. 61, no. 5, pp. 448-454, 2006.

[10] J. M. Lee, J. Yanagawa, K. A. Peebles, S. Sharma, J. T. Mao, and S. M. Dubinett, "Inflammation in lung carcinogenesis: new targets for lung cancer chemoprevention and treatment," Critical Reviews in Oncology/Hematology, vol. 66, no. 3, pp. 208-217, 2008.

[11] K. E. De Visser, A. Eichten, and L. M. Coussens, "Paradoxical roles of the immune system during cancer development," Nature Reviews Cancer, vol. 6, no. 1, pp. 24-37, 2006.

[12] R. Kim, M. Emi, and K. Tanabe, "Cancer immunoediting from immune surveillance to immune escape," Immunology, vol. 121, no. 1, pp. 1-14, 2007.

[13] L. Zitvogel, A. Tesniere, and G. Kroemer, "Cancer despite immunosurveillance: immunoselection and immunosubversion," Nature Reviews Immunology, vol. 6, no. 10, pp. 715727, 2006. 
[14] D. W. Cramer and O. J. Finn, "Epidemiologic perspective on immune-surveillance in cancer," Current Opinion in Immunology, vol. 23, no. 2, pp. 265-271, 2011.

[15] Y. Arnson, Y. Shoenfeld, and H. Amital, "Effects of tobacco smoke on immunity, inflammation and autoimmunity," Journal of Autoimmunity, vol. 34, no. 3, pp. J258-J265, 2010.

[16] N. Kumagai-Takei, M. Maeda, Y. Chen et al., "Asbestos induces reduction of tumor immunity," , Clinical and Developmental Immunology, vol. 2011, Article ID 481439, 9 pages, 2011.

[17] D. Arenberg, "Chemokines in the biology of lung cancer," Journal of Thoracic Oncology, vol. 1, no. 4, pp. 287-288, 2006.

[18] S. Pakkala and S. S. Ramalingam, "Lung cancer in HIVpositive patients," Journal of Thoracic Oncology, vol. 5, no. 11, pp. 1864-1871, 2010.

[19] F. N. Engsig, G. Kronborg, C. S. Larsen et al., "Lung cancer in HIV patients and their parents: a Danish cohort study," $B M C$ Cancer, vol. 11, article 272, 2011.

[20] E. A. Engels, R. J. Biggar, H. I. Hall et al., "Cancer risk in people infected with human immunodeficiency virus in the United States," International Journal of Cancer, vol. 123, no. 1, pp. 187-194, 2008.

[21] C. Jiménez, A. Manrique, E. Marqués et al., "Incidence and risk factors for the development of lung tumors after liver transplantation," Transplant International, vol. 20, no. 1, pp. 57-63, 2007.

[22] E. A. Engels, R. M. Pfeiffer, J. F. Fraumen Jr. et al., "Spectrum of cancer risk among US solid organ transplant recipients," The Journal of the American Medical Association, vol. 306, no. 17, pp. 1891-1901, 2011.

[23] J. E. Heffner, "Diagnosis and management of malignant pleural effusions," Respirology, vol. 13, no. 1, pp. 5-20, 2008.

[24] H. Prado-Garcia, D. Aguilar-Cazares, H. Flores-Vergara, J. J. Mandoki, and J. S. Lopez-Gonzalez, "Effector, memory and naïve CD8+ T cells in peripheral blood and pleural effusion from lung adenocarcinoma patients," Lung Cancer, vol. 47, no. 3, pp. 361-371, 2005.

[25] D. Atanackovic, A. Block, A. De Weerth, C. Faltz, D. K. Hossfeld, and S. Hegewisch-Becker, "Characterization of effusion-infiltrating $\mathrm{T}$ cells: benign versus malignant effusions," Clinical Cancer Research, vol. 10, no. 8, pp. 26002608, 2004.

[26] E. Pace, T. F. Bruno, B. Berenger et al., "Elevated expression of prostaglandin receptor and increased release of prostaglandin E2 maintain the survival of CD45RO+ T cells in the inflamed human pleural space," Immunology, vol. 121, no. 3, pp. 427436, 2007.

[27] M. Okamoto, Y. Hasegawa, T. Hara et al., "T-helper type 1/T-helper type 2 balance in malignant pleural effusions compared to tuberculous pleural effusions," Chest, vol. 128, no. 6, pp. 4030-4035, 2005.

[28] Y. M. Chen, W. K. Yang, C. C. Ting et al., "Cross regulation by IL-10 and IL-2/IL-12 of the helper T cells and the cytolytic activity of lymphocytes from malignant effusions of lung cancer patients," Chest, vol. 112, no. 4, pp. 960-966, 1997.

[29] E. Thunnissen, K. M. Kerr, F. J. Herth et al., "The challenge of NSCLC diagnosis and predictive analysis on small samples. Practical approach of a working group," Lung Cancer, vol. 76, no. 1, pp. 1-18, 2012.

[30] J. M. Kirkwood, L. H. Butterfield, A. A. Tarhini et al., "Immunotherapy of cancer in 2012," CA-A CancerJournal for Clinicians, vol. 62, no. 5, pp. 309-3335, 2012.

[31] K. Yasumoto, T. Hanagiri, and M. Takenoyama, "Lung cancer-associated tumor antigens and the present status of immunotherapy against Non-small-cell lung cancer," General Thoracic and Cardiovascular Surgery, vol. 57, no. 9, pp. 449457, 2009.

[32] N. P. Restifo, M. E. Dudley, and S. A. Rosenberg, "Adoptive immunotherapy for cancer: harnessing the T cell response," Nature Reviews Immunology, vol. 12, no. 4, pp. 269-2281, 2012.

[33] A. O. Gure, R. Chua, B. Williamson et al., "Cancer-testis genes are coordinately expressed and are markers of poor outcome in non-small cell lung cancer," Clinical Cancer Research, vol. 11, no. 22, pp. 8055-8062, 2005.

[34] E. Bria, P. Visca, F. Novelli et al., "Nuclear and cytoplasmic cellular distribution of survivin as survival predictor in resected non-small-cell lung cancer," European Journal of Surgical Oncology, vol. 34, no. 5, pp. 593-598, 2008.

[35] M. Makita, A. Hiraki, T. Azuma et al., "Antilung cancer effect of WT1-specific cytotoxic T lymphocytes," Clinical Cancer Research, vol. 8, no. 8, pp. 2626-2631, 2002.

[36] Y. Oka, A. Tsuboi, T. Taguchi et al., "Induction of WT1 (Wilms' tumor gene)-specific cytotoxic T lymphocytes by WT1 peptide vaccine and the resultant cancer regression," Proceedings of the National Academy of Sciences of the United States of America, vol. 101, no. 38, pp. 13885-13890, 2004.

[37] Y. Ichiki, M. Takenoyama, M. Mizukami et al., "Simultaneous cellular and humoral immune response against mutated p53 in a patient with lung cancer," The Journal of Immunology, vol. 172, no. 8, pp. 4844-4850, 2004.

[38] K. T. Hogan, D. P. Eisinger, S. B. Cupp III et al., "The peptide recognized by HLA-A68.2-restricted, squamous cell carcinoma of the lung-specific cytotoxic T lymphocytes is derived from a mutated elongation factor 2 gene," Cancer Research, vol. 58, no. 22, pp. 5144-5150, 1998.

[39] H. Echchakir, F. Mami-Chouaib, I. Vergnon et al., "A point mutation in the $\alpha$-actinin-4 gene generates an antigenic peptide recognized by autologous cytolytic T lymphocytes on a human lung carcinoma," Cancer Research, vol. 61, no. 10, pp. 4078-4083, 2001.

[40] V. Karanikas, D. Colau, J. F. Baurain et al., "High frequency of cytolytic T lymphocytes directed against a tumor-specific mutated antigen detectable with HLA tetramers in the blood of a lung carcinoma patient with long survival," Cancer Research, vol. 61, no. 9, pp. 3718-3724, 2001.

[41] M. Takenoyama, J. F. Baurain, M. Yasuda et al., "A point mutation in the NFYC gene generates an antigenic peptide recognized by autologous cytolytic $\mathrm{T}$ lymphocytes on a human squamous cell lung carcinoma," International Journal of Cancer, vol. 118, no. 8, pp. 1992-1997, 2006.

[42] P. Van Der Bruggen, C. Traversari, P. Chomez et al., "A gene encoding an antigen recognized by cytolytic $\mathrm{T}$ lymphocytes on a human melanoma," Science, vol. 254, no. 5038, pp. 1643-1647, 1991.

[43] O. Wakabayashi, K. Yamazaki, S. Oizumi et al., "CD4+ T cells in cancer stroma, not CD8+ T cells in cancer cell nests, are associated with favorable prognosis in human non-small cell lung cancers," Cancer Science, vol. 94, no. 11, pp. 1003-1009, 2003.

[44] M. C. Dieu-Nosjean, M. Antoine, C. Danel et al., "Longterm survival for patients with non-small-cell lung cancer with intratumoral lymphoid structures," Journal of Clinical Oncology, vol. 26, no. 27, pp. 4410-4417, 2008.

[45] A. Trojan, M. Urosevic, R. Dummer, R. Giger, W. Weder, and R. A. Stahel, "Immune activation status of CD8+ T cells infiltrating non-small cell lung cancer," Lung Cancer, vol. 44, no. 2, pp. 143-147, 2004. 
[46] I. Yoshino, T. Yano, M. Murata et al., "Tumor-reactive T-cells accumulate in lung cancer tissues but fail to respond due to tumor cell-derived factor," Cancer Research, vol. 52, no. 4, pp. 775-781, 1992.

[47] T. So, M. Takenoyama, M. Mizukami et al., "Haplotype loss of HLA class I antigen as an escape mechanism from immune attack in lung cancer," Cancer Research, vol. 65, no. 13, pp. 5945-5952, 2005.

[48] T. Baba, T. Hanagiri, Y. Ichiki et al., "Lack and restoration of sensitivity of lung cancer cells to cellular attack with special reference to expression of human leukocyte antigen class I and/or major histocompatibility complex class I chain related molecules A/B," Cancer Science, vol. 98, no. 11, pp. 17951802, 2007.

[49] H. Winter, N. K. van den Engel, M. Rusan et al., "Activespecific immunotherapy for non-small cell lung cancer," Journal of Thoracic Disease, vol. 3, no. 2, pp. 105-114, 2011.

[50] L. E. Raez, S. Fein, and E. R. Podack, "Lung cancer immunotherapy," Clinical Medicine \& Research, vol. 3, no. 4, pp. 221-228, 2005.

[51] P. Weynants, J. Thonnard, M. Marchand, M. Delos, T. Boon, and P. G. Coulie, "Derivation of tumor-specific cytolytic Tcell clones from two lung cancer patients with long survival," American Journal of Respiratory and Critical Care Medicine, vol. 159, no. 1, pp. 55-62, 1999.

[52] Y. Saijo, X. Hong, M. Tanaka et al., "Autologous highkilling cytotoxic $\mathrm{T}$ lymphocytes against human lung cancer are induced using interleukin (IL)- $1 \beta$, IL-2, IL-4, and IL6: possible involvement of dendritic cells," Clinical Cancer Research, vol. 5, no. 5, pp. 1203-1209, 1999.

[53] Y. Nagata, T. Hanagiri, M. Takenoyama et al., "Identification of the HLA-Cw $* 0702$-restricted tumor-associated antigen recognized by a CTL clone from a lung cancer patient," Clinical Cancer Research, vol. 11, no. 14, pp. 5265-5272, 2005.

[54] T. So, M. Takenoyama, Y. Ichiki et al., "A different pattern of cytotoxic T lymphocyte recognition against primary and metastatic tumor cells in a patient with nonsmall cell lung carcinoma," Cancer, vol. 103, no. 1, pp. 200-208, 2005.

[55] G. Friedlein, F. El Hage, I. Vergnon et al., "Human CD5 protects circulating tumor antigen-specific CTL from tumormediated activation-induced cell death," The Journal of Immunology, vol. 178, no. 11, pp. 6821-6827, 2007.

[56] M. Barry and R. C. Bleackley, "Cytotoxic T lymphocytes: all roads lead to death," Nature Reviews Immunology, vol. 2, no. 6, pp. 401-409, 2002.

[57] C. A. Klebanoff, L. Gattinoni, and N. P. Restifo, "CD8+ Tcell memory in tumor immunology and immunotherapy," Immunological Reviews, vol. 211, pp. 214-224, 2006.

[58] J. A. Berzofsky, M. Terabe, S. Oh et al., "Progress on new vaccine strategies for the immunotherapy and prevention of cancer," The Journal of Clinical Investigation, vol. 113, no. 11, pp. 1515-1525, 2004.

[59] M. A. Williams and M. J. Bevan, "Effector and memory CTL differentiation," Annual Review of Immunology, vol. 25, pp. 171-192, 2007.

[60] F. Pagès, A. Berger, M. Camus et al., "Effector memory T cells, early metastasis, and survival in colorectal cancer," The New England Journal of Medicine, vol. 353, no. 25, pp. 2654-2666, 2005.

[61] J. Galon, A. Costes, F. Sanchez-Cabo et al., "Type, density, and location of immune cells within human colorectal tumors predict clinical outcome," Science, vol. 313, no. 5795, pp. 1960-1964, 2006.
[62] L. Zhang, J. R. Conejo-Garcia, D. Katsaros et al., "Intratumoral T cells, recurrence, and survival in epithelial ovarian cancer," The New England Journal of Medicine, vol. 348, no. 3, pp. 203-213, 2003.

[63] O. Kawai, G. Ishii, K. Kubota et al., "Predominant infiltration of macrophages and CD8+ T cells in cancer nests is a significant predictor of survival in stage IV nonsmall cell lung cancer," Cancer, vol. 113, no. 6, pp. 1387-1395, 2008.

[64] K. I. Al-Shibli, T. Donnem, S. Al-Saad, M. Persson, R. M. Bremnes, and L. T. Busund, "Prognostic effect of epithelial and stromal lymphocyte infiltration in non-small cell lung cancer," Clinical Cancer Research, vol. 14, no. 16, pp. 52205227, 2008.

[65] E. Ruffini, S. Asioli, P. L. Filosso et al., "Clinical significance of tumor-infiltrating lymphocytes in lung neoplasms," The Annals of Thoracic Surgery, vol. 87, no. 2, pp. 365-372, 2009.

[66] K. Hiraoka, M. Miyamoto, Y. Cho et al., "Concurrent infiltration by CD8 + T cells and CD4+ T cells is a favourable prognostic factor in non-small-cell lung carcinoma," British Journal of Cancer, vol. 94, no. 2, pp. 275-280, 2006.

[67] G. Lucivero, G. Pierucci, and L. Bonomo, "Lymphocyte subsets in peripheral blood and pleural fluid," European Respiratory Journal, vol. 1, no. 4, pp. 337-340, 1988.

[68] L. de Chaisemartin, J. Goc, D. Damotte et al., "Characterization of chemokines and adhesion molecules associated with T cell presence in tertiary lymphoid structures in human lung cancer," Cancer Research, vol. 71, no. 20, pp. 6391-6399, 2011.

[69] Y. M. Chen, C. C. Ting, J. W. Peng et al., "Restoration of cytotoxic $\mathrm{T}$ lymphocyte function in malignant pleural effusion: interleukin-15 versus interleukin-2," Journal of Interferon and Cytokine Research, vol. 20, no. 1, pp. 31-39, 2000.

[70] D. A. Thomas and J. Massagué, "TGF- $\beta$ directly targets cytotoxic T cell functions during tumor evasion of immune surveillance," Cancer Cell, vol. 8, no. 5, pp. 369-380, 2005.

[71] J. S. López-González, D. Aguilar-Cázares, H. Prado-García et al., "Lack of correlation between growth inhibition by TGF- $\beta$ and the percentage of cells expressing type II TGF- $\beta$ receptor in human non-small cell lung carcinoma cell lines," Lung Cancer, vol. 38, no. 2, pp. 149-158, 2002.

[72] D. O. Croci, M. F. Zacarías Fluck, M. J. Rico, P. Matar, G. A. Rabinovich, and O. G. Scharovsky, "Dynamic crosstalk between tumor and immune cells in orchestrating the immunosuppressive network at the tumor microenvironment," Cancer Immunology, Immunotherapy, vol. 56, no. 11, pp. 1687-1700, 2007.

[73] N. P. Weng, K. Liu, M. Catalfamo, Y. Li, and P. A. Henkart, "IL-15 is a growth factor and an activator of CD8 memory T cells," Annals of the New York Academy of Sciences, vol. 975, pp. 46-56, 2002.

[74] C. N. Baxevanis, I. F. Voutsas, O. E. Tsitsilonis, A. D. Gritzapis, R. Sotiriadou, and M. Papamichail, "Tumorspecific CD4+ $\mathrm{T}$ lymphocytes from cancer patients are required for optimal induction of cytotoxic $\mathrm{T}$ cells against the autologous tumor," The Journal of Immunology, vol. 164, no. 7, pp. 3902-3912, 2000.

[75] Y. Q. Chen, H. Z. Shi, X. J. Qin et al., "CD4+CD25+ regulatory $\mathrm{T}$ lymphocytes in malignant pleural effusion," American Journal of Respiratory and Critical Care Medicine, vol. 172, no. 11, pp. 1434-1439, 2005.

[76] E. Y. Woo, C. S. Chu, T. J. Goletz et al., "Regulatory CD4+CD25+ T cells in tumors from patients with early-stage non-small cell lung cancer and late-stage ovarian cancer," Cancer Research, vol. 61, no. 12, pp. 4766-4772, 2001. 
[77] P. DeLong, R. G. Carroll, A. C. Henry et al., "Regulatory T cells and cytokines in malignant pleural effusions secondary to mesothelioma and carcinoma," Cancer Biology and Therapy, vol. 4, no. 3, pp. 342-346, 2005.

[78] H. Tao, Y. Mimura, K. Aoe et al., "Prognostic potential of FOXP3 expression in non-small cell lung cancer cells combined with tumor-infiltrating regulatory T cells," Lung Cancer, vol. 75, no. 1, pp. 95-101, 2012.

[79] G. Esendagli, K. Bruderek, T. Goldmann et al., "Malignant and non-malignant lung tissue areas are differentially populated by natural killer cells and regulatory $T$ cells in non-small cell lung cancer," Lung Cancer, vol. 59, no. 1, pp. 32-40, 2008.

[80] H. Prado-Garcia, D. Aguilar-Cazares, M. Meneses-Flores, J. Morales-Fuentes, and J. S. Lopez-Gonzalez, "Lung carcinomas do not induce T-cell apoptosis via the Fas/Fas ligand pathway but down-regulate CD3 epsilon expression," Cancer Immunology, Immunotherapy, vol. 57, no. 3, pp. 325-336, 2008.

[81] L. Broderick, S. P. Brooks, H. Takita, A. N. Baer, J. M. Bernstein, and R. B. Bankert, "IL-12 reverses anergy to T cell receptor triggering in human lung tumor-associated memory T cells," Clinical Immunology, vol. 118, no. 2-3, pp. 159-169, 2006.

[82] M. O. Kilinc, K. S. Aulakh, R. E. Nair et al., "Reversing tumor immune suppression with intratumoral IL-12: activation of tumor-associated $\mathrm{T}$ effector/memory cells, induction of $\mathrm{T}$ suppressor apoptosis, and infiltration of CD8+ T effectors," The Journal of Immunology, vol. 177, no. 10, pp. 6962-6973, 2006.

[83] H. Dong, S. E. Strome, D. R. Salomao et al., "Tumorassociated $\mathrm{B} 7-\mathrm{H} 1$ promotes T-cell apoptosis: a potential mechanism of immune evasion," Nature Medicine, vol. 8, pp. 793-800, 2002.

[84] C. Blank, T. F. Gajewski, and A. Mackensen, "Interaction of PD-L1 on tumor cells with PD-1 on tumor-specific T cells as a mechanism of immune evasion: implications for tumor immunotherapy," Cancer Immunology, Immunotherapy, vol. 54, no. 4, pp. 307-314, 2005.

[85] G. J. Freeman, E. J. Wherry, R. Ahmed, and A. H. Sharpe, "Reinvigorating exhausted HIV-specific T cells via PD-1-PD1 ligand blockade," The Journal of Experimental Medicine, vol. 203, no. 10, pp. 2223-2227, 2006.

[86] M. Ahmadzadeh, L. A. Johnson, B. Heemskerk et al., "Tumor antigen-specific CD8 $\mathrm{T}$ cells infiltrating the tumor express high levels of PD-1 and are functionally impaired," Blood, vol. 114, no. 8, pp. 1537-1544, 2009.

[87] Y. Zhang, S. Huang, D. Gong, Y. Qin, and Q. Shen, "Programmed death-1 upregulation is correlated with dysfunction of tumor-infiltrating CD8+ $\mathrm{T}$ lymphocytes in human non-small cell lung cancer," Cellular and Molecular Immunology, vol. 7, no. 5, pp. 389-395, 2010.

[88] J. R. Brahmer, C. G. Drake, I. Wollner et al., "Phase I study of single-agent anti-programmed death-1 (MDX1106) in refractory solid tumors: safety, clinical activity, pharmacodynamics, and immunologic correlates," Journal of Clinical Oncology, vol. 28, no. 19, pp. 3167-3175, 2010.

[89] K. Kontani, S. Sawai, J. Hanaoka, N. Tezuka, S. Inoue, and S. Fujino, "Involvement of granzyme B and perforin in suppressing nodal metastasis of cancer cells in breast and lung cancers," European Journal of Surgical Oncology, vol. 27, no. 2, pp. 180-186, 2001.

[90] R. A. Seder and R. Ahmed, "Similarities and differences in CD4+ and CD8+ effector and memory T cell generation," Nature Immunology, vol. 4, no. 9, pp. 835-842, 2003.
[91] V. Appay, P. R. Dunbar, M. Callan et al., "Memory CD8+ T cells vary in differentiation phenotype in different persistent virus infections," Nature Medicine, vol. 8, no. 4, pp. 379-385, 2002.

[92] Y. M. Chen, W. K. Yang, J. Whang-Peng et al., "Restoration of the immunocompetence by IL-2 activation and TCR-CD3 engagement of the in vivo anergized tumor-specific CTL from lung cancer patients," Journal of Immunotherapy, vol. 20, no. 5, pp. 354-364, 1997.

[93] H. R. Kim, K. A. Hwang, S. H. Park, and I. Kang, "IL-7 and IL-15: biology and roles in T-cell immunity in health and disease," Critical Reviews in Immunology, vol. 28, no. 4, pp. 325-339, 2008.

[94] Y. M. Chen, C. M. Tsai, J. Whang-Peng, and R. P. Perng, "Double signal stimulation was required for full recovery of the autologous tumor-killing effect of effusion-associated lymphocytes," Chest, vol. 122, no. 4, pp. 1421-1427, 2002.

[95] T. K. Hoffmann, G. Dworacki, T. Tsukihiro et al., "Spontaneous apoptosis of circulating T lymphocytes in patients with head and neck cancer and its clinical importance," Clinical Cancer Research, vol. 8, no. 8, pp. 2553-2562, 2002.

[96] I. Kuss, A. D. Donnenberg, W. Gooding, and T. L. Whiteside, "Effector CD8+CD45RO-CD27-T cells have signalling defects in patients with squamous cell carcinoma of the head and neck," British Journal of Cancer, vol. 88, no. 2, pp. 223230, 2003.

[97] A. E. Albers, C. Schaefer, C. Visus, W. Gooding, A. B. DeLeo, and T. L. Whiteside, "Spontaneous apoptosis of tumorspecific tetramer+ CD8 + T lymphocytes in the peripheral circulation of patients with head and neck cancer," Head and Neck, vol. 31, no. 6, pp. 773-781, 2009.

[98] I. Caras, A. Grigorescu, C. Stavaru et al., "Evidence for immune defects in breast and lung cancer patients," Cancer Immunology, Immunotherapy, vol. 53, no. 12, pp. 1146-1152, 2004.

[99] E. U. Wieckowski, C. Visus, M. Szajnik, M. J. Szczepanski, W. J. Storkus, and T. L. Whiteside, "Tumor-derived microvesicles promote regulatory $\mathrm{T}$ cell expansion and induce apoptosis in tumor-reactive activated CD8+ T lymphocytes," The Journal of Immunology, vol. 183, no. 6, pp. 3720-3730, 2009.

[100] S. Maher, D. Toomey, C. Condron, and D. BouchierHayes, "Activation-induced cell death: the controversial role of Fas and Fas ligand in immune privilege and tumour counterattack," Immunology and Cell Biology, vol. 80, no. 2, pp. 131-137, 2002.

[101] H. Prado-Garcia, S. Romero-Garcia, J. Morales-Fuentes, D. Aguilar-Cazares, and J. S. Lopez-Gonzalez, "Activationinduced cell death of memory CD8 $+\mathrm{T}$ cells from pleural effusion of lung cancer patients is mediated by the type II Fas-induced apoptotic pathway," Cancer Immunology Immunotherapy, vol. 61, no. 7, pp. 1065-1080, 2012.

[102] D. Toomey, G. Smyth, C. Condron et al., "Infiltrating immune cells, but not tumour cells, express FasL in nonsmall cell lung cancer: no association with prognosis identified in 3-year follow-up," International Journal of Cancer, vol. 103, no. 3, pp. 408-412, 2003.

[103] N. P. Restifo, "Not so Fas: re-evaluating the mechanisms of immune privilege and tumor escape," Nature Medicine, vol. 6, no. 5, pp. 493-495, 2000.

[104] B. Lu and O. J. Finn, "T-cell death and cancer immune tolerance," Cell Death and Differentiation, vol. 15, no. 1, pp. 70-79, 2008.

[105] T. Z. Zaks, D. B. Chappell, S. A. Rosenberg, and N. P. Restifo, "Fas-mediated suicide of tumor-reactive $\mathrm{T}$ cells following 
activation by specific tumor: selective rescue by caspase inhibition," The Journal of Immunology, vol. 162, no. 6, pp. 3273-3279, 1999.

[106] A. Gati, N. Guerra, C. Gaudin et al., "CD158 receptor controls cytotoxic T-lymphocyte susceptibility to tumormediated activation-induced cell death by interfering with Fas signaling," Cancer Research, vol. 63, no. 21, pp. 74757482, 2003.

[107] J. H. Li, D. Rosen, P. Sondel, and G. Berke, "Immune privilege and FasL: two ways to inactivate effector cytotoxic T lymphocytes by FasL-expressing cells," Immunology, vol. 105, no. 3, pp. 267-277, 2002.

[108] S. Radoja, M. Saio, and A. B. Frey, "CD8+ tumor-infiltrating lymphocytes are primed for fas-mediated activation-induced cell death but are not apoptotic in situ," The Journal of Immunology, vol. 166, no. 10, pp. 6074-6083, 2001.

[109] P. Bouillet and L. A. O'Reilly, "CD95, BIM and T cell homeostasis," Nature Reviews Immunology, vol. 9, no. 7, pp. 514-519, 2009.

[110] S. C. Fas, S. Baumann, A. Krueger et al., "In vitro generated human memory-like T cells are CD95 type II cells and resistant towards CD95-mediated apoptosis," European Journal of Immunology, vol. 36, no. 11, pp. 2894-2903, 2006.

[111] R. K. Batra, Y. Lin, S. Sharma et al., "Non-small cell lung cancer-derived soluble mediators enhance apoptosis in activated $\mathrm{T}$ lymphocytes through an $\mathrm{I} \kappa \mathrm{B}$ kinase-dependent mechanism," Cancer Research, vol. 63, no. 3, pp. 642-646, 2003.

[112] T. Das, G. Sa, E. Paszkiewicz-Kozik et al., "Renal cell carcinoma tumors induce $\mathrm{T}$ cell apoptosis through receptordependent and receptor-independent pathways," The Journal of Immunology, vol. 180, no. 7, pp. 4687-4696, 2008.

[113] R. Spooner and Ö. Yilmaz, "The role of reactive-oxygenspecies in microbial persistence and inflammation," International Journal of Molecular Sciences, vol. 12, no. 1, pp. 334352, 2011.

[114] H. Norell, T. M. Da Palma, A. Lesher et al., "Inhibition of superoxide generation upon T-cell receptor engagement rescues Mart-127-35-reactive T cells from activation-induced cell death," Cancer Research, vol. 69, no. 15, pp. 6282-6289, 2009.

[115] A. Takahashi, M. G. V. Hanson, H. R. Norell et al., "Preferential cell death of CD8+ effector memory (CCR7 CD45RA-) T cells by hydrogen peroxide-induced oxidative stress," The Journal of Immunology, vol. 174, no. 10, pp. 60806087, 2005.

[116] C. C. Zarozinski, J. M. McNally, B. L. Lohman, K. A. Daniels, and R. M. Welsh, "Bystander sensitization to activationinduced cell death as a mechanism of virus-induced immune suppression," Journal of Virology, vol. 74, no. 8, pp. 3650$3658,2000$.

[117] K. M. Antoniou, E. Ferdoutsis, and D. Bouros, "Interferons and their application in the diseases of the lung," Chest, vol. 123, no. 1, pp. 209-216, 2003.

[118] B. Castagneto, S. Zai, L. Mutti et al., "Palliative and therapeutic activity of IL-2 immunotherapy in unresectable malignant pleural mesothelioma with pleural effusion: results of a phase II study on 31 consecutive patients," Lung Cancer, vol. 31, no. 2-3, pp. 303-310, 2001.

[119] A. V. Timoshenko, Y. Lan, H. J. Gabius, and P. K. Lala, "Immunotherapy of $\mathrm{C} 3 \mathrm{H} / \mathrm{HeJ}$ mammary adenocarcinoma with interleukin-2, mistletoe lectin or their combination: effects on tumour growth, capillary leakage and nitric oxide
(NO) production," European Journal of Cancer, vol. 37, no. 15, pp. 1910-1920, 2001.

[120] G. B. Ratto, P. Zino, S. Mirabelli et al., "A randomized trial of adoptive immunotherapy with tumor-infiltrating lymphocytes and interleukin-2 versus standard therapy in the postoperative treatment of resected nonsmall cell lung carcinoma," Cancer, vol. 78, no. 2, pp. 244-251, 1996.

[121] G. B. Ratto, M. A. Cafferata, T. Scolaro et al., "Phase II study of combined immunotherapy, chemotherapy, and radiotherapy in the postoperative treatment of advanced non-small-cell lung cancer," Journal of Immunotherapy, vol. 23, no. 1, pp. 161-167, 2000. 


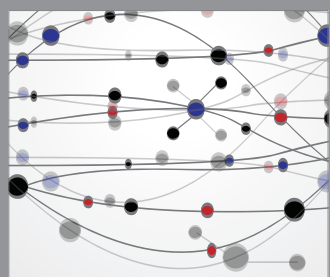

The Scientific World Journal
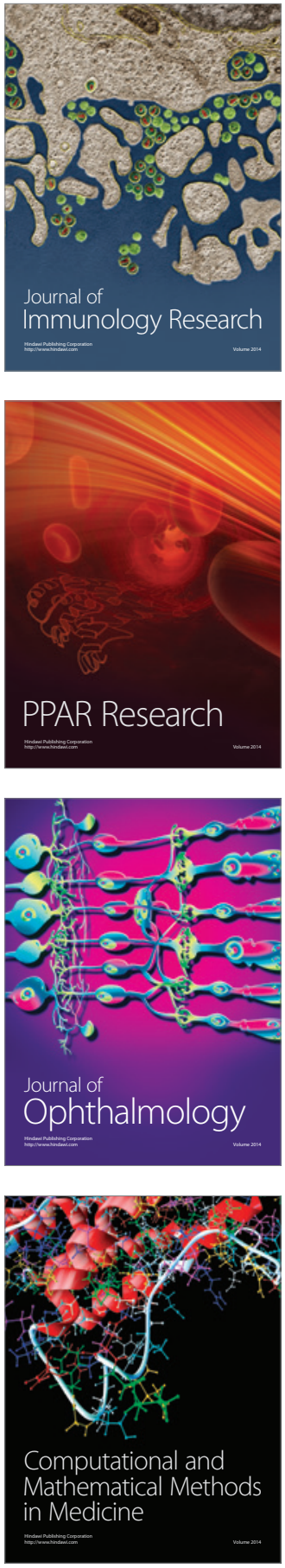

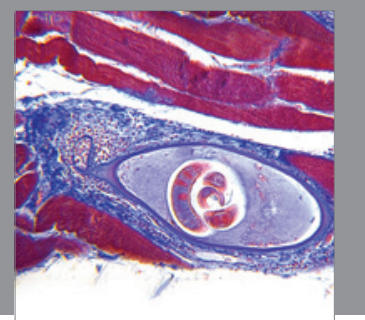

Gastroenterology

Research and Practice
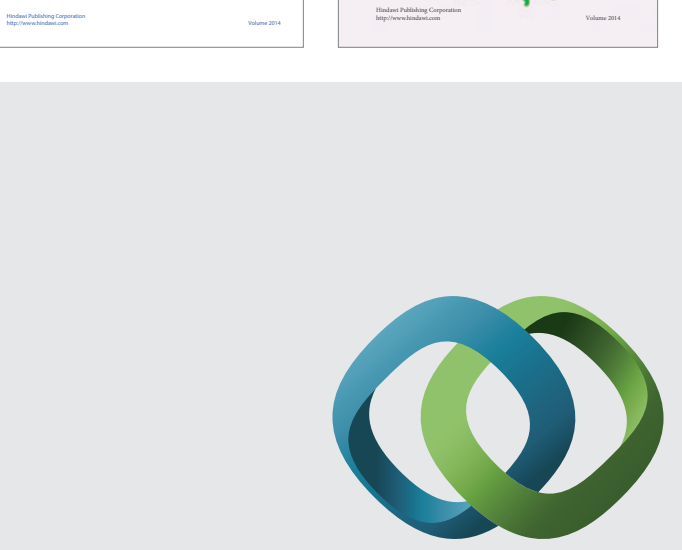

\section{Hindawi}

Submit your manuscripts at

http://www.hindawi.com
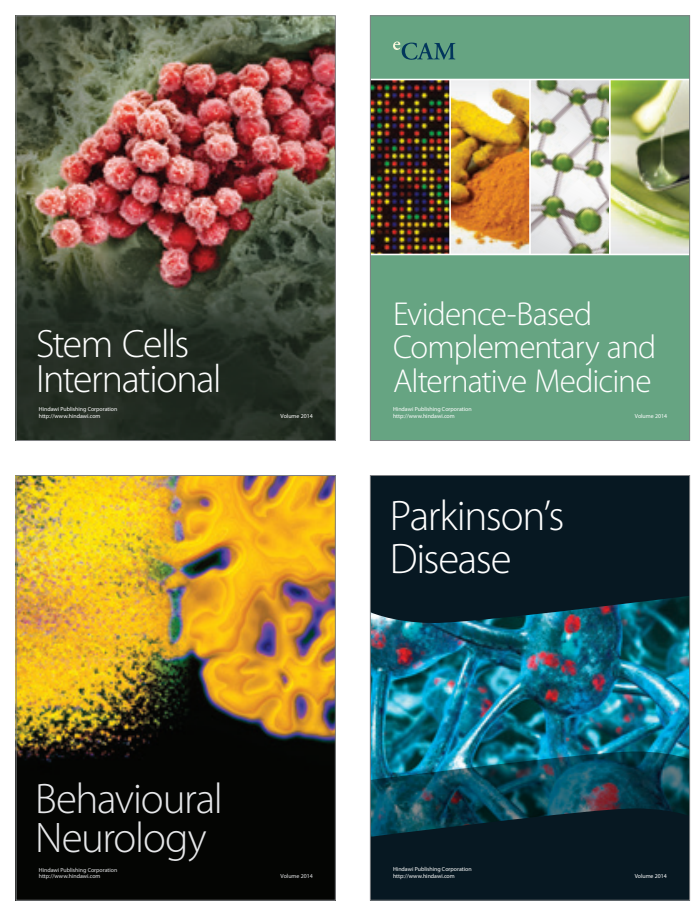

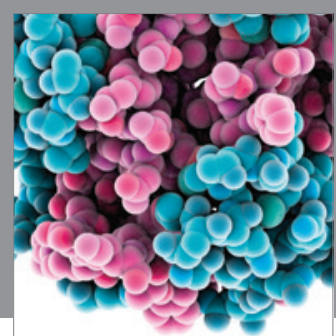

Journal of
Diabetes Research

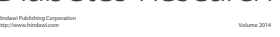

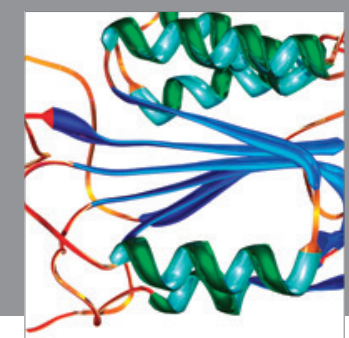

Disease Markers
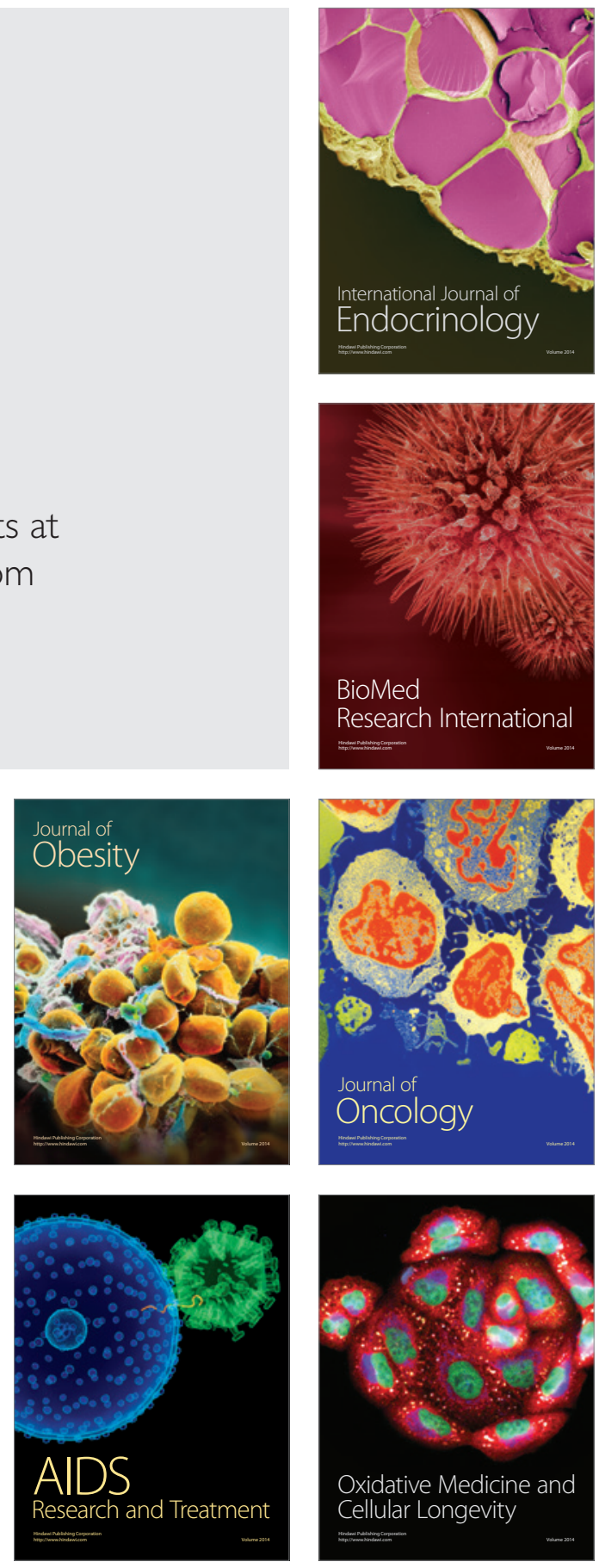